\title{
A IMPORTÂNCIA DA CRECHE NO DESENVOLVIMENTO INFANTIL
}

\author{
Clarice Martins Monteiro de Miranda ${ }^{1}$ \\ Lucilene Regina dos Santos ${ }^{2}$ \\ Marlene Leonarda Moraes de Oliveira ${ }^{3}$ \\ Maria Aparecida dos Santos Oliveira ${ }^{4}$ \\ Maria Zildineth Sergio ${ }^{5}$
}

RESUMO: A creche assume um papel cada vez mais importante na dinâmica familiar e no desenvolvimento da criança. Esses serviços de atendimento à infância também se desenvolvem como estruturas sociais e culturais a partir dos conceitos que cada sociedade constrói para as crianças. Neste artigo, buscou-se investigar as opiniões dos autores acerca da importância das creches no desenvolvimento infantil.

Palavras-chave: Creche. Infância. Desenvolvimento Infantil.

ABSTRACT: Day care plays an increasingly important role in family dynamics and child development. These childcare services also develop as social and cultural structures based on the concepts that each society builds for children. In this article, we sought to investigate the authors' opinions about the importance of day care centers in child development.

Keywords: Daycare. Childhood. Child Development.

\section{INTRODUÇÃO}

O surgimento da creche foi impulsionado no século $X X$ por transformações econômicas, políticas e sociais que deram origem a novas organizações familiares, principalmente no que se refere ao papel social da mulher em relação ao trabalho, às tarefas

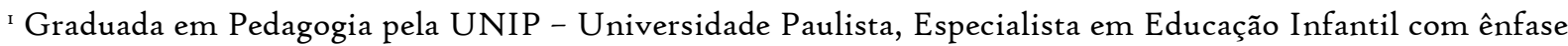
em Educação Especial pela UNISERRA - Faculdade de Educação de Tangará da Serra.

${ }^{2}$ Graduada em Pedagogia pela UNIC - Universidade de Cuiabá, Especialista em Educação Infantil e Letramento pela Faculdade INVEST de Ciências e Tecnologia.

${ }_{3}$ Graduada em Pedagogia pela UFMT - Universidade Federal de Mato Grosso, Especialista em Educação Infantil pela UFMT - Universidade Federal de Mato Grosso.

${ }_{4}^{4}$ Graduada em Pedagogia pela UNICID - Universidade de São Paulo, Especialista em Educação Infantil pela FAUC - Faculdade de Cuiabá.

5 Graduada em Pedagogia pela Faculdade INVEST de Ciências e Tecnologia, Graduada em Biologia pela UNIC - Universidade de Cuiabá, Especialista em Educação Infantil e Séries Iniciais pela Faculdade INVEST de Ciências e Tecnologia.
} 
domésticas, ao cuidado dos filhos e ao ingresso no mercado de trabalho (VIEIRA, HANSEN, \& VIEIRA, 2009).

A preocupação com a saúde e higiene da população pobre também foi um importante propulsor da criação das creches. Em função dessas demandas, seu objetivo era prestar assistência às crianças das camadas pobres da população, por meio de alimentação, cuidado e saúde (PACHECO \& DUPRET, 2004).

No ano de 1996, a Lei de Diretrizes e Bases da Educação Nacional (Brasil, 1996) mudou o foco assistencialista da creche para o enfoque educativo, incluindo-o na primeira etapa da educação básica para atendimento a crianças de zero aos quarenta e sete meses de idade, quer sejam instituições públicas, quer sejam privadas.

Os fatores que contribuíram para que surgisse esse novo modelo de atendimento à infância, destaca-se a Constituição de 1988, o Estatuto da Criança e do Adolescente- ECA (Brasil, 1990), bem como as pesquisas na área da Psicologia, Educação e Sociologia.

Dessa forma, a educação infantil, que já foi caracterizada pelo modelo de substituição das mães de crianças pobres, é entendida como uma formação educacional a serviço de sujeitos que gozam de direitos (SILVA \& SOUZA, 2014).

A criança é um sujeito ativo e participativo, e a noção de poder aprender e mudar sua cultura também tem levado a novas sugestões pedagógicas, descrevendo a creche como um serviço de atendimento para todas as crianças, com o objetivo de cuidar delas e educar.

\section{DESENVOLVIMENTO}

\section{I O cuidar e educar}

O cuidado e a educação são indissociáveis. Para além da dimensão física das crianças, inclui também o respeito e incentivo ao seu desenvolvimento global, garantindo uma educação de qualidade, tendo em conta as suas diferentes necessidades e formas de ocupação e participação na cultura; a parceria entre os primeiros a educação infantil e a família, valorizam seus conhecimentos e experiências (BRASIL, 2010).

Como destacam Gomes, Silva \& Ern (2003), o binômio cuidar/educar envolve o desenvolvimento de ações que favorecem, a todo instante, estimulação visual, olfativa, gustativa, tátil, auditiva, assim como sua socialização. 
Portanto, com o advento dos serviços de cuidados à criança é posta em prática uma ação educativa. É nessa perspectiva integral do cuidar/educar que Moreira \& Lordelo (2002) consideram a creche como estratégia da qualidade de vida da população, das camadas sociais pobres, na medida em que como rede de apoio social e financeiro às famílias, permite reduzir a violência doméstica, fortalecer a escolaridade e reorganizar os valores e as práticas educativas das crianças. Eles mostram que quando uma criança passa um dia na creche, as famílias passam menos tempo juntas, o que reduz o estresse das mães e melhora a in teração mãe-filho.

De acordo com Pacheco \& Dupret (2004), as creches públicas brasileiras, em sua maioria, funcionam de forma precária, com escassez de recursos, pouca infraestrutura e falta de qualificação profissional dos educadores. De acordo com esses autores, grande parte dos profissionais que trabalham nas creches públicas brasileiras tem baixa formação profissional e pautam sua prática, sobretudo, no modelo de atendimento aos cuidados básicos como higiene e alimentação. Esse caráter assistencialista contribui para o empobrecimento e não para a promoção do desenvolvimento da criança. Para esses autores, no caso das famílias que vivem em condições precárias de vida, a creche se torna fundamental no rompimento das práticas mantenedoras da exclusão social.

Cró \& Pinho (20II) destacam a importância da qualidade do contexto e do atendimento dispensado pelas creches no processo educativo. Além disso, esses autores reivindicam o planejamento da prática pedagógica, baseada em uma formação sólida que considere as necessidades e os interesses das crianças, como critérios fundamentais para a garantia da qualidade do processo educativo.

Ainda de acordo com esses mesmos autores realizaram uma pesquisa com educadoras de creches em Portugal, sobre os sentidos que essas profissionais atribuem a sua prática profissional. Os resultados mostraram que a maioria das educadoras não opta pela profissão que exerce e considera importante o educador possuir competências e saberes específicos para o desempenho de suas funções. Essas participantes apontaram como principais funções do educador na creche: promover as primeiras manifestações de autonomia, organizar e gerir o ambiente educativo, planejar atividades pedagógicas, estabelecer uma rotina diária e prestar cuidados básicos às crianças. 
Destaca-se, também, a pesquisa realizada por Coelho (2009) sobre a compreensão de educadoras em relação às práticas educativas na creche. Os resultados mostraram que as participantes apontaram como objetivos educacionais: a indissociabilidade entre cuidar e educar, a importância da estimulação, com ênfase nos processos de aprendizagem, o estabelecimento de limites e a organização da rotina na creche. Sobre o currículo da creche, a maior parte das educadoras apresentou uma perspectiva maturacional do desenvolvimento, apesar de se mostrarem sensíveis ao papel ativo que as crianças desempenham nesse processo.

Para Rosemberg \& Artes (2012) é importante considerar a construção do significado que se atribui à creche, se está alicerçado na compreensão desse contexto como "uma etapa educacional legítima, um direito de todas as crianças de o a 3 anos”, ou se persiste o significado da creche associado à assistência, ou ainda, se as vagas para crianças de o a 03 anos de idade estão sendo preenchidas por crianças maiores, especialmente em estabelecimentos de educação infantil, denominados e registrados como creches.

Pode-se afirmar que os serviços de atendimento à infância são desenvolvidos a partir de concepções e expectativas que cada sociedade constrói para as crianças e ajudam a configurar as práticas de cuidado e educação ideal (HARKNESS \& SUPER, 2013).

Estudos Harkness \& Super, (1992); Musatti, (2003) têm mostrado que pais e educadores de diversas culturas assumem perspectivas diferentes quando avaliam os aspectos ligados à organização do ambiente educativo nas instituições, ao comportamento, à qualificação e ao desempenho dos educadores ou especificamente à dimensão curricular. Ademais, as concepções sobre desenvolvimento e educação estão relacionadas com a organização do contexto físico e social e com a forma como os educadores conduzem suas práticas educativas. Por sua vez, tais processos são construídos por meio da interação sociocultural do indivíduo e apresentam variações entre contextos (HARKNESS \& SUPER, 2013).

Para Becker (2008), quanto mais nova a criança, menor o prestígio profissional e menor a remuneração das educadoras. Ainda segundo esse autor, a desvalorização desses educadores tem raízes no modelo assistencialista que deu origem às creches, modelo em que as educadoras assumiam o papel materno nos cuidados à criança. Sendo assim, à educadora, então considerada cuidadora, bastava saber cuidar de crianças, dispensando formação 
profissional e, consequentemente, sua remuneração seria baixa em relação aos demais profissionais da educação infantil e das outras etapas do ensino.

\subsection{O papel da creche no desenvolvimento infantil}

Volpato \& Mello (2005) sobre a função da creche, os quais mostraram ênfase na alimentação e cuidado, e, ainda, que as educadoras se consideravam substitutas do papel maternal, como também mais aptas a desenvolvê-lo que as mães das crianças, uma vez que estas não ofereciam o cuidado, o carinho e a atenção necessários ao desenvolvimento infantil. Vê-se, pois, a ênfase no papel assistencialista da creche, como instituição que busca suprir necessidades básicas da criança, a exemplo da alimentação, cuidados físicos e afeto, substituindo o papel parental.

Como preconizado pela LDB (Brasil, 1996), entende-se que o cuidado, a alimentação e o carinho também devem fazer parte do cotidiano da creche; porém, enquanto instituição educativa, baseada em conhecimentos intencionalmente organizados e potencializadores dos processos de desenvolvimento e aprendizagem, a educação a ser realizada na creche vai além daquela realizada no contexto familiar.

No que se refere à afetividade, essa faz parte do processo de ensino-aprendizagem, conferindo ao educador um papel de destaque na qualidade das trocas sociais que estabelece com a criança e, portanto, não se caracteriza como práticas assistencialistas, substitutivas do papel materno.

Todavia, o desenvolvimento infantil se processa além dos aspectos biológicos, tendo em vista que esses são necessários, porém não suficientes para que a criança se desenvolva culturalmente. Ademais, esse processo não é linear, pois se constrói a partir da inserção da criança no contexto histórico e cultural (VYGOTSKY, i994; ASBAHR \& NASCIMENTO, 2013).

Assim, a criança encontra-se imersa em um contexto sociocultural, transformandoo na medida em que é transformada por ele, participando ativamente de seu desenvolvimento e da sua aprendizagem. Nessa perspectiva, o educador é um ator fundamental no processo de aprendizagem da criança, mediando sua relação com o 
conhecimento, desafiando suas potencialidades e possibilitando diferentes experiências complementares às da família.

Asbahr \& Nascimento (2013), a escola não pode esperar que a criança amadureça para aprender; é preciso criar as condições para que a maturação aconteça. Ao considerar o não urbano como contexto de vida, é importante ressaltar uma educação que dialogue com as características socioculturais concretas dessa realidade, com os modos de vida da infância desse lugar.

Esse diálogo entre contextos é preconizado pelo Ministério da Educação (Brasil, 2009a), segundo o qual o currículo da educação infantil deve ser baseado nas interações e práticas educativas intencionalmente atreladas às experiências concretas da vida cotidiana, para a aprendizagem da cultura. Apesar de ser um direito de toda a criança, não apenas daquelas cujas mães trabalham, as creches, no contexto não urbano, ainda são escassas.

Silva et al. (2012) argumentam que, parte dessa concepção é fundamentada na representação saudosista e romantizada do não urbano como espaço em que família é extensa, a educação da criança é compartilhada por outros familiares e vizinhos e, portanto, as crianças não precisam da creche. Tal concepção implica a creche como lugar para cuidar das crianças e dar assistência às famílias, e não como contexto educativo.

Moreira \& Lordelo (2002), a creche representa para as camadas sociais empobrecidas uma oportunidade de elevação da qualidade de vida da população, na medida em que atua como uma rede de apoio social e econômico. Oportuniza, ainda, maior autonomia às mulheres e o seu acesso às políticas públicas, na proporção em que possibilita a sua participação no mercado de trabalho, na vida social, contribuindo para a redução da desigualdade e violência de gênero. Aponta-se ainda, que a creche nos contextos estudados pode representar um fator de proteção à criança, pois de acordo com as educadoras, muitas delas ficavam sozinhas nas ruas ou em casa de pessoas desconhecidas, para que os pais pudessem sair para trabalhar.

Além do papel social da creche na organização familiar, essa se constitui um direito de toda a criança, direito à educação pública e de qualidade. Sem desconsiderar a importância do atendimento às necessidades básicas do desenvolvimento infantil, o caráter educativo da creche não pode ser deixado em segundo plano, sobretudo devido ao fato de que educar e cuidar está intimamente associado e são objetivos priorizados na educação infantil. 
Decerto, para além de ser um direito a todas as crianças de 04 a 36 meses, a creche necessita apresentar critérios de qualidade, seja em que contexto for.

Por outro lado, destaca-se a importância da formação profissional destas educadoras, para o desenvolvimento de práticas pedagógicas e educativas que incorporem as características próprias do modo de vida das crianças e famílias do contexto onde estão inseridas.

\subsection{Papel do educador no desenvolvimento da criança}

Coelho (2009), em seu estudo diz que na medida em que a aprendizagem é vista como espontânea e sequencial, e as competências da criança são desconsideradas nesse processo, a exemplo, do evitar que determinados conhecimentos, os quais já fazem parte do cotidiano extraescolar da criança, sejam-lhe expostos, por considerar que essa ainda não está “pronta” para processá-los, como por exemplo contar até dez.

Esse pensamento condiz com a perspectiva de que o desenvolvimento já está predeterminado e que evolui com o tempo. Porém, é preciso considerar que, muito antes de chegarem à escola, as crianças já apresentam conhecimentos da cultura escrita, pois vivenciam no seu dia a dia o mundo letrado, por meio de gibis, livros, jornais, músicas, que correspondem às práticas sociais de uso da leitura e da escrita (VYGOTSKY, 1994).

No caso daquelas crianças em que esse contato com a cultura escrita é mais restrito, a creche e a escola representam contextos importantes para o contato com essas práticas, ao contrário de restringi-las.

As diretrizes curriculares nacionais para a Educação Básica (Brasil, 2013), orientam que os educadores compreendam sua atuação profissional como uma parceria com o trabal ho das famílias na educação das crianças, considerando que cada contexto tem suas especificidades na criação de diferentes ambientes e papéis para seus membros.

Carvalho (2014) chama a atenção para a ênfase atribuída ao afeto na caracterização do trabalho docente. Segundo essa autora, à luz da pedagogia da infância, a afetividade temse tornado um estereótipo para qualificar o docente como bom profissional, constituindo um elemento definidor da vocação do indivíduo para o exercício da docência, e o professor passou a ser visto como naturalmente afetivo. 
Para Carvalho (2014), tais estereótipos surgiram a partir das supostas teorias sobre a privação de afeto das famílias em relação aos seus filhos, cabendo ao professor suprir essa necessidade. Com esses argumentos, a autora não pretende desqualificar o papel do afeto no processo de aprendizagem e desenvolvimento infantil.

O que preocupa, segundo esta autora, são a naturalização e supremacia atribuídas ao afeto no exercício da docência, em que a formação do professor, assim como os processos históricos e culturais que a sustentam, são desconsiderados. Dessa forma, o afeto continua sendo um elemento importante para o desenvolvimento e a aprendizagem da criança, mas não pode ser imposto ao educador como um atributo natural para o exercício da docência, desqualificando sua formação e conhecimentos teóricos práticos.

Ramos \& Salomão (2013) \& Almeida \& Cunha (2003) sobre as concepções de educadores a respeito do desenvolvimento infantil, os quais mostraram representações da criança como objeto de cuidado e afeto. Para Almeida \& Cunha (2003), essa representação ilustra o lugar social para o qual a criança foi preparada, um lugar social ideológico, na medida em que a criança é vista como um ser desprovido, não plenamente agente, competente e responsável.

Em relação à disciplina, entendida como o estabelecimento de limites ao comportamento da criança e a aprendizagem de hábitos educativos, também reflete a concepção da criança como ser passivo, que absorve as influências do meio, além do entendimento de que há períodos específicos para a absorção desses conhecimentos.

Nesse sentido, o educador, como detentor dos conhecimentos, estaria transmitindoos às crianças, de acordo com a sua prontidão para aprender, conhecimentos esses, voltados para o ensino da disciplina e os bons costumes, que buscam o controle e moralização das crianças. A importância atribuída à disciplina, ao controle do comportamento infantil expressa uma relação desigual de poder, em que a passividade e obediência da criança são comportamentos valorizados pelos professores e incentivados na interação.

A concepção de que a disciplina é um dos objetivos da educação infantil foi encontrada em muitas pesquisas com educadores da educação infantil (GOMES, 2008; JORGE, REIS, \& NASCIMENTO, 2008; RAMOS \& SALOMÃO, 2013).

\section{CONCLUSÃO}


A creche desempenha um papel importante no desenvolvimento da criança. As experiências das crianças que vivem neste contexto ampliam a sua socialização e aprendizagem, e a creche deve superar a exclusão social, especialmente para as crianças que vivem em contextos especiais. A questão é que as condições socioeconômicas não são estáveis. Esse cuidado é considerado importante para a criança na creche, no entanto, as funções sociais das creches não podem se limitar a elas.

Com objetivos profissionais, os educadores têm a tarefa de estimular o desenvolvimento das crianças da educação infantil. No entanto, existe uma visão madura da aprendizagem, pois as crianças precisam de maturidade para adquirir certos conhecimentos e acreditam que as práticas educacionais não podem ir além do que adquiriram no passado, ou seja, do ponto de vista do educador, a aprendizagem não precede o resultado do desenvolvimento.

Vygotsky (1994) acredita que estudar na escola orienta e renova o processo de desenvolvimento interno. Além disso, ressalta-se a necessidade de suprir a falta de afeto aos pré-escolares no cumprimento de seu papel profissional de professora de educação infantil. Logo, caberia a elas, educadoras, enquanto profissionais capacitadas para o desempenho de sua profissão oferecer-lhes o afeto e a atenção que precisam. Esse resultado representa a visão de que as crianças pobres estão sendo carentes não apenas econômica, mas também emocionalmente, o que é consistente com a perspectiva da educação compensatória. Além disso, as opiniões desses profissionais quanto ao contexto de seu trabalho dizem respeito às atividades educativas realizadas com as crianças (HARKNESS \& SUPER, 2013).

Neste sentido, a formação profissional é dirigida às crianças, tendo em vista que o seu desenvolvimento é deliberadamente influenciado, em particular nas suas interações com os educadores, e que a qualidade da interação é uma atividade planejada, pode contribuir para o conhecimento das mudanças, dos seus direitos e necessidades.

\section{REFERÊNCIAS BIBLIOGRÁFICAS}

ALMEIDA, Angela Maria de Oliveira; CUNHA, Gleicimar Gonçalves. Representações sociais do desenvolvimento humano. Psicologia: Reflexão e Critica, 2003. I6(I), I47-I55. 
ASBAHR, Flávia da Silva Ferreira; NASCIMENTO, Carolina Picchetti. Criança não é Manga, não Amadurece: conceito de maturação na teoria histórico-cultural. Psicologia: Ciência e Profissão, 2013, 33(2), 414-427.

BECKER, Fernanda da Rosa. A educação infantil no Brasil: a perspectiva do acesso e do financiamento. Revista Ibero-americana de Educación, 2008, 47, I4I-155.

BRASIL. Ministério da Educação. Programa Mais Educação - passo a passo por Maria Eliane Santos et al. Brasília: MEC - Secad, 20o9a.

COELHO, Ana. Intencionalização educativa em Creche. Revista Ibero-americana de Educación, 2009, 49(5), i681-5653.

CRÓ, Maria de Lurdes; PINHO, Ana Mafalda. A primeira infância e a avaliação do desenvolvimento pessoal e social. Revista Ibero-americana de Educación, 20II, 56(I), I68I5653.

GOMES, R. C. O. Concepções de mães e professoras de educação infantil. In V. Vasconcellos, L. Aquino, \& A. Dias (Ed.). Psicologia e educação infantil, 20o8, (p. I47-166). Araraquara: Junqueira \& Marin Editores.

HARKNESS, Sara; SUPER, Charles M. Cultura e política no desenvolvimento na primeira infância. Enciclopédia sobre o Desenvolvimento na Primeira Infância, 2013. Disponível em https://www.enciclopedia-crianca.com. Acesso em 04/07/202I.

VIEIRA, Viviane; HANSEN, Jante; VIEIRA, Mauro Luis. Psicologia Escolar na Educação Infantil: atuação e prevenção em saúde mental. Barbarói, n. 31, ago-dez. p. 72-89, 2009.

MUSATTI, Tullia. Programas educacionais para a pequena infância na Itália. Revista Brasileira de Educação, 2003, 24, 66-77.

MOREIRA, Lúcia Vaz de Campos; LORDELO, Eulina da Rocha. Creche em ambiente urbano pobre: ressonâncias no ecossistema desenvolvimental. Interação em Psicologia, 2002, 6(I), I-I3.

PACHECO, Ana Lúcia Paes de Barros; DUPRET, Leila. Creche: Desenvolvimento ou sobrevivência? Psicologia USP, 2004, 15(3), 103-ı16.

RAMOS, Deborah Dornellas; SALOMÃO, Nádia Maria Ribeiro. Interação educadoracriança em creches públicas: estilos linguísticos. Psicologia em Estudo, 2012, 17 (I), 15-25.

ROSEMBERG, Flávia; ARTES, Amélia. O rural e o urbano na oferta de educação para crianças de até 6 anos. In Barbosa, M. C. S. et al. (org.), Oferta e demanda de educação infantil no campo (pp. 13-69). Porto Alegre: 2012, Evangraf. 
SILVA, Ana Paula Soares; PASUCH, Jaqueline; SILVA, J. B. Educação infantil do campo. São Paulo: Cortez, 2012.

VOLPATO, Cláudia Fernandes; MELO, Suely Amaral. Trabalho e Formação dos Educadores de creche em Botucatu: Reflexões críticas. Cadernos de Pesquisa, 2005, 35(I26), $723-745$.

VYGOTSKY, Lev Semenovitch. A formação social da mente. São Paulo: Martins Fontes, 1994. 